\title{
Distribution of head and neck lesions diagnosed on histopathology in Western U.P.: A retrospective study
}

\author{
Shweta Agarwal ${ }^{1, *}$, Ranjan Agrawal ${ }^{2}$, Prachi Gupta ${ }^{3}$, Prabodh Kumar ${ }^{4}$ \\ ${ }^{1}$ Assistant Professor, ${ }^{2}$ Professor, ${ }^{3}$ DCP, ${ }^{4}$ Professor \& HOD, Dept. of Pathology, Rohilkhand Medical College \& \\ Hospital, Bareilly, Uttar Pradesh, India
}

*Corresponding Author:

Email: dr.shwetagarwal@gmail.com

\begin{abstract}
Introduction: Head and neck lesions are very common in day to day practice. These diseases range from common cold to the uncommon, malignant neoplasms. These lesions are responsible for very high morbidity and mortality. Factors known to contribute to the risk of developing head and neck cancer are smokeless tobacco (Pan masala, soda), alcohol, HPV viral infections, etc. Smokeless tobacco is commonly used in Northern part of India, especially in Uttar Pradesh.

Aim: To evaluate the diagnosis, frequency and histopathological subtypes of head and neck lesions and their distribution in different age groups and sex in Western Uttar Pradesh.

Settings and Design: A retrospective study of 3 years from March 2014 to February 2017 was conducted and the data were collected from the archives of the department. The data were analyzed using SPSS version 15.0.

Materials and Methods: All the biopsies from the head and neck region, which were submitted for histopathology in the Post Graduate department of Pathology, Rohilkhand Medical College and Hospital, Bareilly, were reviewed and analyzed for their demographic profile, age, gender, site and diagnosis. The lesions were then categorized accordingly as inflammatory, benign and malignant.

Results: All the lesions of head and neck region, diagnosed on histopathology were included in the present study. A total of three hundred twenty one biopsies were studied, including 212 (66\%) males and 109 (34\%) females (M: $\mathrm{F}=1.9: 1) .197(61 \%)$ of the cases were benign, followed by $69(22 \%)$ malignant and $55(17 \%)$ inflammatory lesions.

The maximum numbers of malignant cases were in the age group of 41 to 50 years with Squamous cell carcinoma as the most common histopathological type. The most common site of malignant lesions was the oral cavity. The maximum benign lesions were in the 11-20 years age group.

Conclusions: The present study helped us in assessing the frequency as well as the different histopathological types of head and neck lesions in different age groups and gender in this part of the country.
\end{abstract}

Keywords: Benign, Head and Neck, Inflammatory, Malignant, North India.

Received: $20^{\text {th }}$ March, 2017

\section{Introduction}

Head and neck lesions are very common in day to day practice. These lesions can be seen in all the age groups. "Head and neck" region includes a wide anatomic area:- scalp and forehead, oral cavity, upper airways, including the nose, larynx, and nasal sinuses, pharynx and upper esophagus, ears, eye, skin, soft tissue, lymph nodes, and salivary glands. As there are a large number of tissues in this region, a variety of lesions can be seen. The differential diagnosis includes branchial cysts, thyroglossal cysts, dermoid cysts, lymphangioma, hemangioma, lymphadenitis, sialadenitis, neoplasia etc. ${ }^{1}$

Head and neck neoplasia (HNN) are the $7^{\text {th }}$ most common malignancy worldwide, accounting for $23 \%$ of all cancers in males and $6 \%$ in females. ${ }^{2,3}$ Tobacco, alcohol, low socioeconomic conditions related to poor hygiene, poor diet and viral infections are very common
Accepted: 04 ${ }^{\text {th }}$ August, 2017

culprits for majority of these lesions. ${ }^{4-} 6$ Also lesions like leucoplakia, oral lichen planus, sub mucosal fibrosis and Plummer vinsons syndrome, are known risk factors. If proper preventive measures and screening programmes are carried out, majority of these neoplasms can be prevented at an early stage.

The presence of a mass involving nodal and /or glandular structures in this region often creates confusion in the minds of physicians. Also, many primary as well as metastatic lesions are responsible for head and neck swellings. Therefore open surgical biopsy with histopathological examination is the gold standard for diagnosis.

\section{Aim}

The present study was conducted to evaluate the histopathological subtypes and frequency of head and neck lesions and their distribution in 
different age groups and gender in a tertiary care centre.

\section{Materials and Methods}

\section{Source of data}

The present study was carried out in the Post Graduate Pathology department at Rohilkhand Medical College and Hospital, a tertiary care hospital in Western Uttar Pradesh.

\section{Study design}

Cross-sectional analytical study.

\section{Method of collecting data}

A retrospective study of 3 years from March 2014 to February 2017 was planned. The present study was conducted on patients in and around Bareilly region. Data was collected year-wise with context to age, gender, site involved and the histopathological findings.

Two experienced pathologists independently reported on the H\&E sections. At times help of immunohistochemical and/or histochemical staining were taken for confirmation of diagnosis. The histological diagnosis was established by the peer slide review; however, if disagreement existed amongst the pathologists, a consensus was reached upon mutual discussion or a third senior pathologist's opinion was sought of.

Patients of all ages with lesions in the head, forehead, eye, ear, nose, oral cavity, and neck were included in the study. Intra cranial lesions, tissue with normal histology and lesions with no specific pathology were excluded from the study.
The demographical profile of the patients was archived from the departmental data base.

The lesions were classified into three main categories i.e. Inflammatory, Benign and Malignant.

\section{Statistical analysis}

In this cross-sectional study data was collected was tabulated and analyzed systematically by the use of appropriate statistical methods. They were then compared to similar studies done previously and conclusions were drawn.

\section{Result}

A total of 321(three hundred and twenty one) biopsies were included in the present study with age ranging from 5 months to 75 years. Table 1 and Fig. 1 depict the distribution of lesions as per the age and sex. The maximum number of patients belonged to the age group 1120 and 31 to 50 years. There were $212(66 \%)$ males and 109 (34\%) females, with a male to female ratio of 1.9:1. Our study showed lesions comprising of $197(61.3 \%)$ benign, $69(21.4 \%)$ malignant and 55(17.3\%) inflammatory. The malignant lesions showed a male-female ratio of $2: 1$ with $46(14.3 \%)$ males and $23(7.1 \%)$ females. This difference in frequency of lesions in males and females was found to be statistically significant. The malignant lesions were observed more commonly in the age group of 41-50 years followed by 51-60 years. The least common age group for malignant lesions was the pediatric age group, i.e. less than 20 years. The maximum patients with benign lesions belong to 11-20 years, followed by 21-30 and 31-40 years age group.

Table 1: Classification of head and neck lesions as per the Age and Sex

\begin{tabular}{|l|lr|rr|rr|rr|}
\hline \multicolumn{1}{|c|}{ Age } & \multicolumn{2}{|c|}{ Inflammatory } & \multicolumn{2}{c|}{ Benign } & \multicolumn{2}{c|}{ Malignant } & \multicolumn{2}{c|}{ Total } \\
\hline & M & $\mathbf{F}$ & $\mathbf{M}$ & $\mathbf{F}$ & $\mathbf{M}$ & $\mathbf{F}$ & $\mathbf{M}$ & $\mathbf{F}$ \\
\hline $0-10$ & 2 & 2 & 10 & 4 & 1 & 0 & 13 & 6 \\
\hline $11-20$ & 14 & 11 & 48 & 13 & 2 & 1 & 64 & 25 \\
\hline $21-30$ & 6 & 4 & 20 & 15 & 3 & 1 & 29 & 20 \\
\hline $31-40$ & 3 & 2 & 23 & 16 & 8 & 6 & 34 & 24 \\
\hline $41-50$ & 5 & 2 & 16 & 8 & 14 & 7 & 35 & 17 \\
\hline $51-60$ & 1 & 1 & 8 & 5 & 9 & 4 & 18 & 10 \\
\hline $61-70$ & 1 & 0 & 7 & 1 & 8 & 3 & 16 & 4 \\
\hline$>60$ & 1 & 0 & 1 & 2 & 1 & 1 & 3 & 3 \\
\hline Total & 33 & 22 & 133 & 64 & 46 & 23 & 212 & 109 \\
\hline Percentage & $10.3 \%$ & $6.8 \%$ & $41.5 \%$ & $19.9 \%$ & $14.4 \%$ & $7.1 \%$ & $66.2 \%$ & $34.1 \%$ \\
\hline
\end{tabular}




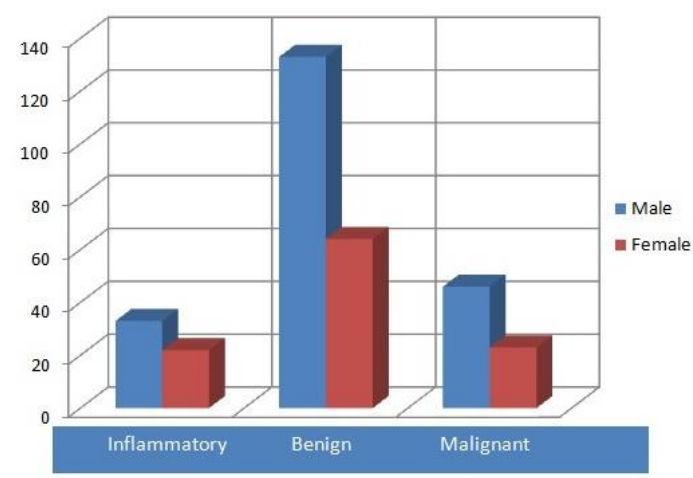

Fig. 1: Bar diagram to show lesions according to sex

Table 2 depicts the distribution of the malignant lesions according to the age group.

In our study Squamous cell carcinoma was found to be the most common cancer and was more common in the age group 41 to 50 years followed by 51 to 60 years. Hodgkin's lymphoma was found in children, i.e. below 10 years and Non Hodgkin's Lymphoma in young children (11-20years age group) and adults (31-40 years age group). Basal Cell Carcinoma was observed in patients more than 70 years of age. Mebomian gland carcinoma was found in patients more than 40 years of age. Sebaceous cell carcinoma, mucoepidermoid carcinoma, malignant melanoma were observed in patients above 60 years of age. Adenoid cystic carcinoma was observed in the 31 to 40 years age group.

Table 2: Classification according to age and malignant histopathological findings

\begin{tabular}{|c|c|c|c|c|c|c|c|c|c|c|c|c|}
\hline 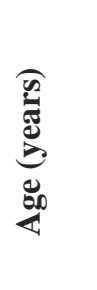 & 勇 & 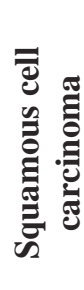 & 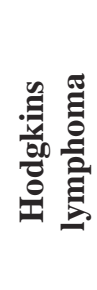 & 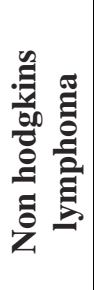 & 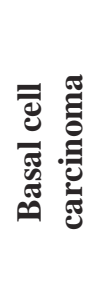 & 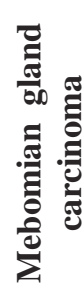 & 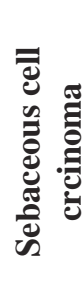 & 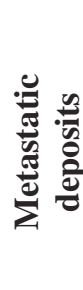 & 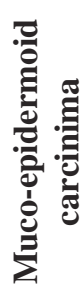 & 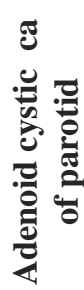 & 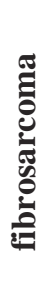 & 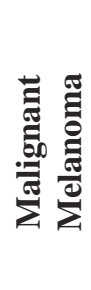 \\
\hline $0-10$ & 17 & & 1 & & & & & & 1 & & 1 & \\
\hline $11-20$ & 60 & & & 1 & & & & 1 & & & & \\
\hline $21-30$ & 28 & 3 & & & & & & 1 & & & & \\
\hline $31-40$ & 42 & 11 & & 1 & & & & & & 1 & & \\
\hline $41-50$ & 23 & 20 & & & & 1 & & & & & & \\
\hline 51-60 & 17 & 12 & & & & & & 1 & & & & \\
\hline $61-70$ & 8 & 6 & & & & 1 & 1 & & 1 & & & 1 \\
\hline$>70$ & 2 & 1 & & & 2 & & & 1 & & & & \\
\hline Total & 197 & 53 & 1 & 2 & 2 & 2 & 1 & 2 & 2 & 1 & 1 & 1 \\
\hline
\end{tabular}

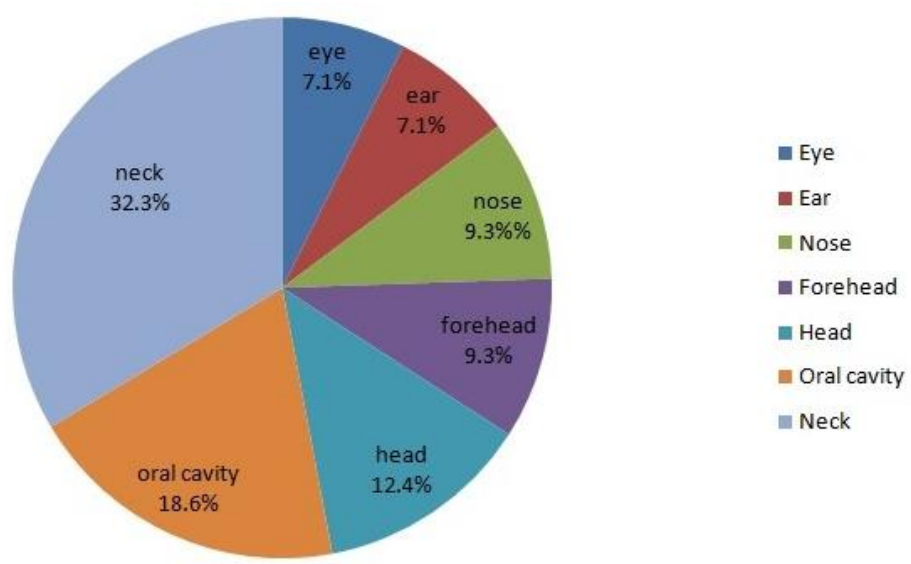

Fig. 2: Pie diagram to show involvement of sites 
Table 3 shows sites involved by benign and malignant lesions. Of all the Ocular lesions 18 (5.6\%) were benign and $5(1.5 \%)$ were malignant, which included malignant melanoma (Fig. 3a), basal cell carcinoma, mebomian gland carcinoma and sebaceous cell carcinoma (Fig. 3c).
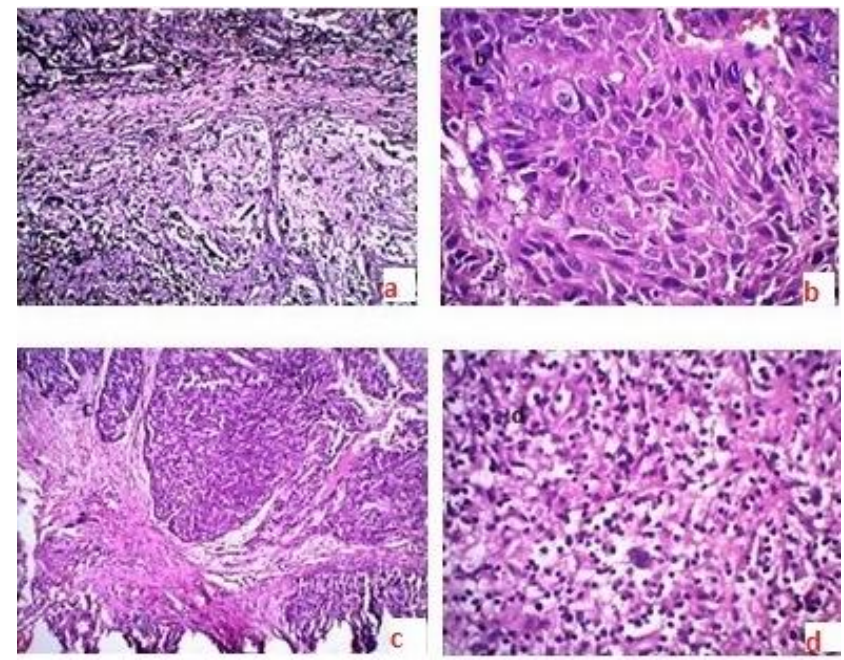

Fig. 3: Showing microscopic picture: a: Malignant melanoma (ocular) (100X, H\&E); b: Squamous cell carcinoma (oral cavity) $(400 X, H \& E)$; c: Mucoepidermoid carcinoma (parotid gland) (100X, H\&E); d: Hodgkin's lymphoma (cervical lymph node) (400X, H\&E)

In ear lesions, all cases $(7.1 \%)$ were benign including one case of capillary hemangioma.

In nose majority of the lesions were benign lesions $(8.7 \%)$ and few were malignant $(0.6 \%)$ including squamous cell carcinoma, Non Hodgkin's lymphoma.

In the oral cavity frequency of benign and malignant lesions was equal i.e. around $10 \%$. The commonest malignant lesion was squamous cell carcinoma (Fig. 3b).

Scalp and forehead lesions together constituted around $21 \%$ including trichilemmal cyst, pilomatricoma, fibrosarcoma, malignant melanoma, squamous cell carcinoma and basal cell carcinoma.

Neck region included supra-clavicular, cervical, supra glottis, parotid, submandiular, thyroid and cervical areas. There were $84(26.1 \%)$ benign and inflammatory lesions and 20(6.2\%) malignant lesions in the neck region as depicted in Table 3. The malignant lesions observed in neck were squamous cell carcinoma, adenoid cystic carcinoma of parotid gland, mucoepidermoid carcinoma (Fig.3c) and Hodgkin's lymphoma (Fig. 3d).

The commonest site for occurrence of benign lesions was neck and the commonest site for malignant lesions was the oral cavity (Table 3 )

Table 3: Classification of sites involvement in benign and malignant lesions

\begin{tabular}{|l|l|c|c|c|c|c|c|}
\hline S. N. & Sites & $\begin{array}{c}\text { Benign and } \\
\text { inflammatory } \\
(\mathbf{n})\end{array}$ & $\%$ & $\begin{array}{c}\text { Malignant } \\
(\mathbf{n})\end{array}$ & $\%$ & $\begin{array}{c}\text { Total } \\
(\mathbf{n})\end{array}$ & $\%$ \\
\hline 1 & Eye & 18 & $5.6 \%$ & 5 & $1.5 \%$ & 23 & $7.1 \%$ \\
\hline 2 & Ear & 23 & $7.1 \%$ & 0 & & 23 & $7.1 \%$ \\
\hline 3 & Nose & 28 & $8.7 \%$ & 2 & $.6 \%$ & 30 & $9.3 \%$ \\
\hline 4 & Forehead & 26 & $8.1 \%$ & 4 & $1.2 \%$ & 30 & $9.3 \%$ \\
\hline 5 & Head & 39 & $12.1 \%$ & 5 & $1.5 \%$ & 44 & $12.4 \%$ \\
\hline 6 & $\begin{array}{l}\text { Oral } \\
\text { cavity }\end{array}$ & 34 & $10.5 \%$ & 33 & $10.2 \%$ & 67 & $18.6 \%$ \\
\hline 7 & Neck & 84 & $26.1 \%$ & 20 & $6.2 \%$ & 104 & $32.3 \%$ \\
\hline Total & & 252 & $78.2 \%$ & 69 & $21.2 \%$ & 321 & \\
\hline
\end{tabular}

Benign lesions observed included fibroepithelial polyps, fibrous epulis, mucocele, ranula, fibroma, leucoplakia, dermoid cyst, nasolabial cyst, basal cell adenoma, pleomorphic adenoma, sebaceous 
adenoma, squamous cell papilloma (Fig 4a), myoepithelioma( in a 40 year male patient with submandibular region swelling)(Fig 4b), neurofibroma( in a 15 year female patient with pre auricular swelling and 14 year male patient with swelling in upper eyelid) (Fig 4c), cavernous hemangioma(Fig $4 d)$.

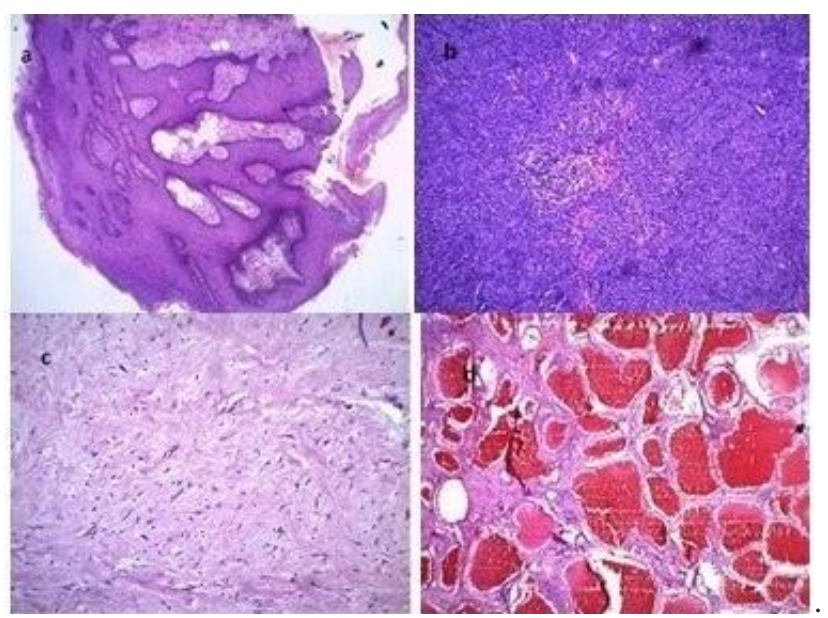

Fig. 4: Low power view showing: a: Squamous cell papilloma of tongue (100X, H\&E); b: Myoepithelioma, left side parotid reagion (100X, H\&E); c: Neurofibroma left side neck (100X, H\&E); d: Cavernous hemangioma of left eye brow (100X, H\&E)

Rare lesions in the study included trichoepithelioma in a 17 year female patient presenting as midline neck swelling, spindle cell lipoma in a 42 year male patient with forehead swelling (Fig 5a). A case of acrospiroma in a 50 year male patient in occipital region (Fig 5b), two cases of mebomian gland carcinoma in 61year and 50 year male patient in the upper eye lid. We also reported Sebaceous cell carcinoma in a 65 year male patient, in the left eyelid (Fig 5c). We noted 7cases of pilomatricoma in patients of all age group with the common site as scalp and cheek (Fig 5d).
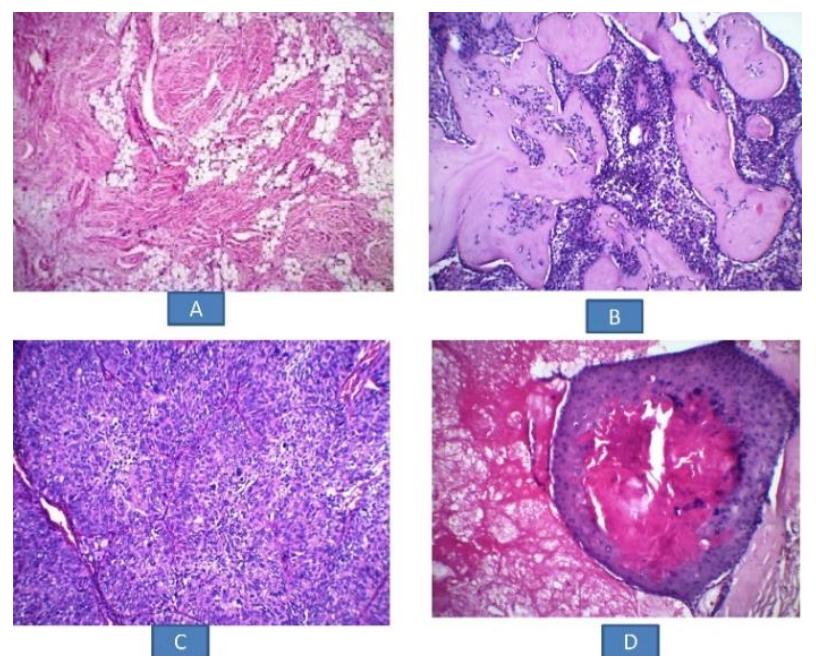

Fig. 5: Showing microscopic view: a: Spindle cell lipoma, forehead swelling (100 X, H \&E); b: Acrospiroma occipital region (100X, H\&E); c: Sebaceous cell carcinoma,eyelid region (100 X, H\&E); d: Pilomatricoma scalp swelling (400X, H\&E)

\section{Discussion}

Head and neck involves a wide anatomic area. The present study included a variety of lesions that are present in this area. Knowledge about the type of lesion and their frequency always helps in the management of the patients.
The nature of lesion determines whether a patient can be managed conservatively or has to be subjected to a major surgical procedure and in malignant lesion whether chemotherapy or radiotherapy is required. Since FNAC has certain limitations and pitfalls, it decreases the 
diagnostic accuracy, making histopathological examination as the gold standard..$^{6,7}$

It is well known that neoplasias are the major cause of deaths among all Head and Neck lesions. ${ }^{8}$ According to the literature in 2013 the head and neck cancers globally affected around 4 million people and resulted in around 3lakhs deaths annualy. ${ }^{9}$ Head and neck cancers are known to be the seventh most common cancer and the ninth most frequent cause of death from cancer. ${ }^{9}$ In India these accounts for $23 \%$ of all cancers in males and $6 \%$ in females and about $5 \%$ of all child hood malignancies. ${ }^{10,11}$ The major symptoms of head and neck cancer are nonhealing ulcers, difficulty in breathing, difficulty in swallowing, change in voice etc.

It should be cautioned that the present cohort study constituted only patients referred for histopathological assessments; hence, a higher frequency of SCC and potentially malignant disorders could have been observed.

Tobacco, alcohol, poor hygiene, few viral infections like HPV 16,18,33, chronic irritation, exposure to radiation are common causes of the Head and neck cancers. Also the variation in the distribution of cancers by head and neck sub-site can be seen according to the relative distribution of major risk factors. ${ }^{10}$

The head and neck lesions can be seen in all age groups. Our study comprised of 321 biopsies with age ranging from 5 months child to 75 year old patient. In our study the maximum number of $89(27.7 \%)$ biopsies was reported in the 11-20 years age group. This may be due to the high frequency of these lesions in this age group and secondly, the parents of children and young adults are more worried and seek early medical attention than elderly patients ${ }^{10}$. Sharma $\mathrm{M}$ et al in their study found maximum number of cases in 40-50 years age group. ${ }^{10}$ Lei $\mathrm{F}$ et al found the maximum number of cases in 50-59 years age group. ${ }^{11}$ Urooj A et al observed the maximum number of cases in less than 30 years age group, which was very near to our study. ${ }^{12}$ This may be due to variation in sample size and geographic locations.

The present study shows that males were more commonly affected than females. Similar observation was done by Mehrotra $\mathrm{R}$ et al, Sharma $\mathrm{M}$ et al, Lei $\mathrm{F}$ et al, Urooj $\mathrm{A}$ et al and Manjari M et al. ${ }^{9-14}$

Most lesions in the current study were benign lesions (61.4\%), followed by the malignant $(21.5 \%)$ then inflammatory/infective lesions (17.1\%), which was compatible with the findings of Jones \& Franklin and Sharma $\mathrm{M}$ et al. ${ }^{10,16}$ But our study doesn't match with Lei $\mathrm{F}$ et al as they reported the least number of benign lesions in their study. ${ }^{11}$

Also, many national studies, including ours, shows that inflammatory and non- neoplastic lesions were mainly responsible for head and neck masses while the neoplastic pathology were more common in different international studies. ${ }^{14,15}$

It was observed that maximum number of benign lesions were in the pediatric age group i.e. less than 20 years age. While Sharma M et al found them in 20-50 years age group and Lei $\mathrm{F}$ et al found them in 50-59 years age group. The literature also supports our study as it says that head and neck malignancies are rare in children accounting for only $5 \%$ of all pediatric malignant neoplasms. ${ }^{9-11}$

Data as observed in the present study show that the oral cavity is the most common site of malignant lesion followed by the neck, which is similar to the data studied by Mehrotra $\mathrm{R}$ et al, Sharma $\mathrm{M}$ et al and Manjari M et al. ${ }^{9,10,13}$

Previous studies have indicated that in males, oral cavity and larynx were predominantly involved followed in order by pharynx; whereas in females oral cavity was the preponderant site involved. ${ }^{16}$ In the present study also, the predominant site involved was oral cavity in both males as well as females.

Table 4 shows the comparison table depicting various studies. It can be interpretated that head and neck lesions can be seen in all age groups with benign lesions as more common than the malignant ones. Males are commonly affected. The most common site for malignant lesion is the oral cavity.

The grade and metastatic deposits of oral cancer at the time of detection is important as it determines the treatment plan as well as the prognosis of the patient. ${ }^{20,21}$

During reporting changes such as tissue regeneration, metaplasia or chronic persistent irritation should be kept in mind. These changes may at times be related to false positive reporting. On the contrary, cystic changes, necrosis or hemorrhage may lead to false negative reporting. ${ }^{20}$

There are certain limitations if we interpret data from a single institution. This data may reflect the specific patient population attending the hospital and not the community as a whole, for which the wide survey is required.

Our study is rare in its kind as it involves all the benign and malignant lesions of head and neck lesions in one study. 


\section{Conclusions}

Through our study we conclude that biopsy remains the gold standard for the diagnosis of head and neck lesions. The present cohort study describes the frequency, age and sex distribution in a Western Uttar Pradesh population referred for histopathological examination. It showed trends similar to previous reports from other institutions with different information, probably due to the difference in criteria and different geographic distribution in their study. Oral Squamous cell carcinoma constitutes the highest percentage of all the malignancies in the head and neck region. Though head \& neck malignancies are a serious issue, good awareness, education, and early diagnosis can reduce their incidence.

\section{References}

1. Flint PW, Harkar LA. (eds); Mc Guirt, Differential diagnosis of neck masses. In Cummings CW, Cummings Otolaryngology Head and Neck Surgery $4^{\text {th }}$ edition Elsevier Mosby 2005; Vol 3:pp 2542.

2. Ahluwalia H, Gupta SC, Singh M, Gupta SC, Mishra V, Singh PA. Spectrum of head and neck cancers at Allahabad.J Otolaryngol Head Neck Surg. 2001;53:16-20.

3. National Cancer Registry Programme-Biennial Report (1988-89) of the National Cancer Registry Programme. New Delhi: Indian Council of Medical Research, 1992;3-42.

4. Gupta PC, Sinor PN, Bhonsle RB, Pawar VS, Mehta HC. Oral submucous fibrosis in India: a new epidemic? Natl Med J India 1998;11:113-6.

5. Sankaranarayanan R, Masuyer E, Swaminathan R, Ferlay J, Whelan S. Head and neck cancer: a global perspective on epidemiology and prognosis. Anticancer Res. 1998;18:4779-86.

6. Mehrotra R, Singh M, Kumar D, Pandey AN, Gupta RK, Sinha US. Age specific incidence rate and pathological spectrum of oral cancer in Allahabad. Indian J Med Sci 2003;57:400-4.

7. Patt BS, Schaefer SD, Vuitch: Role of Fine Needle Aspiration in the evaluation of Neck masses. Med clin North AM 1993;77(3):611-23.

8. Rathod GB, Parmar P. Fine needle aspiration cytology of swellings of head and neck region. Indian J Med Sci 2012;66:49-54.

9. Mehrotra R, Singh M, Gupta RK, Singh M, Kapoor AK. Trends of prevalence and pathological spectrum of head and neck cancers in North India. Ind J Canc 2005;42:89-93.

10. Sharma M, Sharma A, Gandhi S, Khajuria A, Goswami KC. Histopathological pattern of head and neck lesions-a two year retrospective hospital based study. Int J Res Med Sci 2017;5:1282-7.

11. Lei F, Chen PH, Chen JY, Wang WC, Lin LM, Huang HC.Retrospective study of head and neck lesions in a cohort of referral Taiwanese patients. Head and Face medicine. 2014;10:28.
12. Urooj A, Mirza T, Ali A, Agha MA, Rassol S.Frequency of head and neck lesions according to histopatholohical diagnosis.J Dow Univ Health Sciences Karachi. 2011;5:70-3.

13. Manjari M, Popli R, Paul S, Gupta VP, Kaholon SK. Prevalence of oral cavity, pharynx, larynx and nasal cavity malignancies in Amritsar, Punjab. Indian J Otolaryngol Head Neck Surg 1999;48:191-5.

14. Ponder TB, Smith D, Ramzy I. Lympadenopathy in children and adolescent: Role of fine needle aspiration in management . Cancer Detect Prev.2000;24:228-33.

15. Jones AV, Franklin CD: An analysis of oral and maxillofacial pathology found in adults over a 30year period. J Oral Pathol Med. 2006;35:392-401.

16. Bhurgri Y, Bhurgri A, Usman A, Pervez S, Kayani N, Bashir I et al. Epidemiological review of head and neck cancers in Karachi. Asian Pac J Cancer Prev. 2006;7(2):195-200.

17. Ramachandra NB. The hierarchy of oral cancer in India. Int J Head Neck Surg. 2012;3:143-6.

18. Maniyar AU, Patel HL, Parmar BH. Study of Cytodiagnosis of Head and Neck Neoplastic Lesions and comparision with histopathology. RRJMHS 2013;2(2):54-9.

19. Scully C, Began J. Oral Squamous Cell Carcinoma overview. Oral Oncol. 2009;45:301-8.

20. Van der Schroeff MP, Baatenburg de, Jong Rj. Staging and Prognosis in head and neck Cancer. Oral Oncol. 2009;45:356-60.

21. Mohamed MH, Hitam S, Brito-Mutunayagam S, Yunus MRM. Role of FNAC in neck masses.J Curr Surg 2013;3(1):19-23. 